\title{
Relational uncertainty in service dyads
}

\section{Kreye, Melanie}

Published in:

International Journal of Operations and Production Management

Link to article, DOI:

10.1108/IJOPM-11-2015-0670

Publication date:

2017

Document Version

Peer reviewed version

Link back to DTU Orbit

\section{Citation $(A P A)$ :}

Kreye, M. (2017). Relational uncertainty in service dyads. International Journal of Operations and Production Management, 37(3), 363-381. https://doi.org/10.1108/IJOPM-11-2015-0670

\section{General rights}

Copyright and moral rights for the publications made accessible in the public portal are retained by the authors and/or other copyright owners and it is a condition of accessing publications that users recognise and abide by the legal requirements associated with these rights.

- Users may download and print one copy of any publication from the public portal for the purpose of private study or research.

- You may not further distribute the material or use it for any profit-making activity or commercial gain

- You may freely distribute the URL identifying the publication in the public portal

If you believe that this document breaches copyright please contact us providing details, and we will remove access to the work immediately and investigate your claim. 


\title{
Relational uncertainty in service dyads
}

\begin{abstract}
:
Purpose: Relational uncertainty determines how relationships develop because it enables the building of trust and commitment. However, relational uncertainty has not been explored in an inter-organisational setting. This paper investigates how organisations experience relational uncertainty in service dyads and how they resolve it through suitable organisational responses to increase the level of service quality.

Design/methodology/approach: We apply the overall logic of Organisational Information-Processing Theory (OIPT) and present empirical insights from two industrial case studies collected via semi-structured interviews and secondary data.
\end{abstract}

Findings: The findings suggest that relational uncertainty is caused by the partner's unresolved organisational uncertainty, i.e. their lacking capabilities to deliver or receive (parts of) the service. Furthermore, we found that resolving the relational uncertainty increased the functional quality while resolving the partner's organisational uncertainty increased the technical quality of the delivered service.

Originality: We make two contributions. First, we introduce relational uncertainty to the OM literature as the inability to predict and explain the actions of a partnering organisation due to a lack of knowledge about their abilities and intentions. Second, we present suitable organisational responses to relational uncertainty and their effect on service quality.

Keywords: Servitization; case study; uncertainty; organisational informationprocessing theory 


\section{Introduction}

Despite the potential of servitization (Vandermerwe and Rada 1988), the implementation frequently falls below the expectations of manufacturing companies. Only $21 \%$ succeed in implementing a service strategy and $25 \%$ even incur losses with their service business (Baveja et al. 2004, Neely 2008). Various suggestions have been given regarding the causes of these observations which can be linked to the different operational capabilities that service providers need in comparison to manufacturers (Reim et al. 2016). In particular, ensuring service business success depends on the service quality delivered to the customer (Cronin et al. 2000). However, in servitization, quality levels are difficult to control or even to evaluate in practice (Hawkins et al. 2015). This challenges providers' abilities to ensure that they have met customer expectations. Furthermore, different approaches are needed to manage service staff and time due to the high level of operational flexibility required to respond to customer needs (Hawkins et al. 2015). Thus, many servitized manufacturers face high challenges to implementing a service strategy and performing service operations successfully.

These challenges in terms of, for example, evaluating service quality, meeting customer expectations, or managing service staff can be conceptualised as uncertainty. Uncertainty is the lack of knowledge which arises from not definite, not known or not reliable information (Kreye et al. 2012). Different types of uncertainty can be defined depending on their origin in relation to the provider. The literature traditionally differentiates between external and internal sources of uncertainty and describe each with their unique characteristics (Benedettini et al. 2015). External sources are typically referred to as environmental uncertainty, defined as the unpredictability of a company's external environment (Milliken 1987, Fynes et al. 2004). Environmental uncertainty can arise from, for example, market fluctuations (Beckman et al. 2004) and technology 
changes (Oosterhuis et al. 2011). Internal sources of uncertainty arise from the gap between the capabilities an organisation possesses and the capabilities it needs (Galbraith 1974) and have been identified as the main challenge for servitized firms (Benedettini et al. 2015). These internal sources can arise because servitized manufacturers need new capabilities with regard to sales (Reinartz and Ulaga 2008) and managing service staff (Hawkins et al. 2015) as described above. To conceptualise these internal sources of uncertainty in relation to an organisation, we term them organisational uncertainty. This conceptualisation allows us to differentiate it from environmental uncertainty.

The differentiation into environmental and organisational uncertainty reflects classic organisation theory of e.g. traditional manufacturing firms. However, in servitization, additional processes become important. Service providers are required to build and maintain close and long-term customer relationships (Vargo and Lusch 2008). Services are dependent on the symbiotic inputs from both provider and customer (Lacoste and Johnsen 2015) and therefore processes of production and consumption have to be aligned (Schmenner 1986). Service providers thus require additional relational capabilities in order to facilitate the exchange of information and address occurring problems and disagreements in a speedy manner (Srivastava et al. 2001, Kreye et al. 2015). Without relational capabilities, providers are unable to process information in the service dyad. To conceptualise the customer relationship as a potential uncertainty source, we propose the concept of relational uncertainty.

Relational uncertainty has not been investigated in service dyads where two organisations form a relationship. Specifically, the literature lacks a conceptualisation and characterisation of relational uncertainty in service dyads. It further lacks management suggestions for suitable organisational responses to relational uncertainty. 
Reducing relational uncertainty is important because relational factors such as information exchange and communication affect the perception of service quality in the service dyad (Breidbach et al. 2013). This research thus focuses on relational uncertainty as a novel concept in the servitization literature.

This research explores the following research questions: (i) How do organisations experience relational uncertainty in service dyads? (ii) How do organisations reduce relational uncertainty through suitable organisational responses to increase service quality? We base our investigations on the fundamental logic of Organisational Information-Processing Theory (OIPT) because of its conceptualisation of uncertainty as a starting point of organisational activities (Galbraith 1974, Hult et al. 2004). We develop a conceptual framework which we investigate empirically with indepth case studies of two service dyads set in the UK electronics sector. This research contributes to the literature in two ways. First, we conceptualise and characterise relational uncertainty in service dyads as a distinct concept from traditional uncertainty types. Second, we identify suitable organisational responses to reduce relational uncertainty and we describe their effects on service quality.

\section{Theoretical background}

This section presents the theoretical background based on a literature review. Specifically, we review service dyads as the area of concern for our research. Then we present the literature on uncertainty in service dyads. We will draw out the relevant concepts for operationalisation of relational uncertainty in service dyads, relevant organisational responses and service quality. Finally, the literature is summarised in a conceptual framework. 


\subsection{Service dyads}

Servitized manufacturers are required to operate in service dyads which are long-term and close relationships between provider and customer (Vargo and Lusch 2008). In service dyads, the service encounter is embedded in a series of exchanges and transactions are planned and administered (Tax et al. 2013). Service dyads include contractual relations and joint ownership of the outcome (Dwyer et al. 1987). They are thus particularly relevant for Business-to-Business (B2B) relationships such as servitized arrangements.

In services dyads, the customer has multiple touch points with the provider (Grönroos 2011, Sampson 2012). Reversely, a service provider uses multiple channels to deliver the service, including the use of technology and personal channels (Rosenbloom 2007). A service provider needs the capability of integrating the different channels to deliver the outcome of the service package (Rosenbloom 2007, Grönroos 2011). This can pose a challenge in the service dyad due to the increased level of complexity with regard to information exchange and communication (Breidbach et al. 2013). Thus, the nature of the relationship in the service dyad can cause uncertainty due to the broad set of capabilities needed from both partners.

\subsection{Uncertainty in service dyads}

This research adopts the overall logic of OIPT because it describes uncertainty as a central challenge of organisations and a motivator to collect and process relevant information (Galbraith 1974, Hult et al. 2004). OIPT applies a specific definition of uncertainty - typically defined as a lack of information-processing capabilities (Galbraith 1974) - and differentiates uncertainty from equivocality which refers to the ambiguity of conflicting interpretations of a piece of information (Daft and Lengel 
1986). Additional information serves to reduce uncertainty but can increase equivocality (Daft and Lengel, 1986). It is thus uncertainty that constitutes the driver of organisational activities and decision-making (Ruffini et al. 2000). As described above, uncertainty is also a key challenge of servitized manufacturers (Benedettini et al. 2015).

We utilise the overall logic of traditional OIPT which links three elements: uncertainty, information-processing capabilities and performance (Galbraith 1974, Hult et al. 2004). We expand on the concepts of traditional OIPT as follows. First, we investigate the concept of relational uncertainty instead of task uncertainty defined in early works of OIPT (Galbraith 1974). Second, we investigate organisational responses to relational uncertainty rather than focusing on information-processing capabilities in particular. Third, we conceptualise performance as service quality due to its suitability in the context of services (Cronin and Taylor 1994). For the focus of this research, we formulate the following logic as depicted in Figure 1: relational uncertainty (cause) motivates organisational responses (effect) in the service dyad to reduce the uncertainty and hence increase service quality (aim).

\section{<Please insert Figure 1 about here $>$}

\subsubsection{Relational uncertainty as the cause}

The concept of relational uncertainty stems from social psychology where it is a core concept to explain how individuals form relationships (Berger 1986). In social psychology, relational uncertainty is defined as "the inability to predict and explain others' actions" (Kellermann and Reynolds 1990, p. 5). It arises because of a lack of knowledge regarding the partner's attitudes, feelings and behaviour (Knobloch and Solomon 1999). It explains how people communicate and determines the development of relationship characteristics such as trust and commitment, the engagement in negotiations and the experience of conflict (Knobloch and Solomon 1999). It also 
causes information-seeking behaviour regarding, for example, the partner's attitudes (Knobloch and Solomon 1999). Thus, relational uncertainty and the motivation to reduce it determine how inter-personal relationships are formed and develop over time (Berger 1986).

Relationship characteristics described in the social psychology literature have also been highlighted for inter-organisational relationships such as service dyads. For example, negotiations are an important process for aligning expectations in contractual relationships (Lacoste and Johnsen 2015). Contract negotiations often define the future nature of the collaboration in the service dyad (Kreye et al. 2014). Similarly, conflicts have been described in inter-organisational relationships and need to be resolved quickly to mitigate adversarial behaviour (Carey et al. 2011). "Soft factors" such as trust and commitment develop over the duration of inter-organisational relationships (Ulaga and Eggert 2006). Thus, inter-organisational relationships share important characteristics with inter-personal relationships. Due to these similarities, we propose to investigate the concept of relational uncertainty in service dyads. Specifically, this research focuses on characterising relational uncertainty in service dyads and identifying its effect on organisational responses to increase service quality.

\subsubsection{Organisational responses as the effect of relational uncertainty}

In current literature, no empirical or theoretical insights exist on suitable organisational responses to relational uncertainty due to the lack of exploring the concept in this context. However, some suggestions can be derived from the literature on strategic alliances, organisational partnership management and supplier-buyer relationships. Various capabilities are potentially relevant in this context including relational governance mechanisms which define an organisation's ability to operate in interorganisational relationships and benefit from the collaboration (Srivastava et al. 2001). 
This may be particularly relevant for providers' front-office staff because of the high level of customer contact (Zomerdijk and de Vries 2007, Kreye 2016). Relationally capable organisations create relationship-specific assets and routines (Dyer and Singh 1998) which over time can increase trust and confidence between the partners (Bastl et al. 2012). Thus, relational governance mechanisms may be suitable organisational responses to relational uncertainty.

Relational governance mechanisms can be differentiated into formal and informal activities (Cousins et al. 2006). Formal activities can include prescribed routines to solve problems (Poppo and Zenger 2002), communication guidelines and processes (Lui and Ngo 2004). It can also include legal bonds between the partners that are enforced through contracts (Carey et al. 2011). Informal activities can include social routines and behaviour (Dyer and Singh 1998). For example, front-office staff such as service engineers may engage in informal information exchange with customer employees in addition to scheduled service visits (Kreye et al. 2015). Thus, organisations can engage in a large variety of activities with regards to the formality of procedures with potentially varying effects on reducing relational uncertainty and different impact on service quality.

\subsubsection{Service quality as the aim of reducing relational uncertainty}

Service quality is a long-term attitude (Cronin and Taylor 1994) and includes elements of subjective evaluation (Grönroos 1988, Cronin and Taylor 1994) that is affected by various factors such as economic performance (Antioco et al. 2008), competitor offerings (Eggert and Ulaga 2002) and customer satisfaction (Grönroos 1988). Thus, different measures of service quality have been defined and discussed in the literature. One example is SERVQUAL which conceptualises service quality as the gap between expected and received service (Parasuraman et al. 1988). Another example is 
SERVPERF (Cronin and Taylor 1994) which focuses on the perception of the received service. These existing measures of service quality have been investigated predominantly in Business-to-Consumer (B2C) industries such as restaurants, banks or dry cleaning (Parasuraman et al. 1988, Cronin and Taylor 1994). Service dyads are characterised by the long-term nature of the engagement (see Section 2.1) and the evaluation of service quality may thus be impacted by additional factors such as perceptions of the relationship quality (Ulaga and Eggert 2006, Grönroos 2011). Relationship quality describes the customer's perceived trade-off between benefits of the delivered service and sacrifices in terms of relationship-specific investments (Ulaga 2003). Thus, existing measures of service quality have limited applicability to service dyads.

Two dimensions are included in most measures of service quality (Grönroos 1988): the technical and the functional quality. The technical quality describes what is delivered and includes factors such as performance output or equipment up-time (Caldwell and Howard 2014). It can usually be assessed objectively through, for example, a comparison to the contractually agreed service requirements (Roehrich and Lewis 2010, Kreye et al. 2014). The functional quality describes how the customer receives the service and includes factors such as reliability (of employees and materials), responsiveness and appearance and quality of physical facilities and equipment (Cronin and Taylor 1994). This is more difficult to measure because it can be influenced by the customer's expectations and prior experiences with competitor offerings (Parasuraman et al. 1988). We utilise this differentiation into technical and functional quality to evaluate the service quality in service dyads.

\subsection{Conceptual framework}

This research investigates three elements to answer our research questions based on the 
overall logic of OIPT. First, relational uncertainty in service dyads is investigated. Here we aim specifically to identify characteristics of relational uncertainty in service dyads. Second, we identify effective organisational responses to reduce relational uncertainty. This research will investigate specifically the suitability of different relational governance mechanisms including formal and informal links (Cousins et al. 2006). Third, we investigate the impact of organisational responses on service quality. We focus specifically on technical and functional quality (Grönroos 1988) as frequently described indicators in the literature.

\section{Method}

Due to the exploratory nature of this research, we employ a qualitative research approach via case studies for the following three reasons. First, case studies offer the possibility of investigating a context-specific phenomenon (Barratt et al. 2011) where contextual influences can be identified and analysed. This is particularly relevant for research on services as findings often depend on contextual factors such as the industrial sector (Baines and Lightfoot 2014). Second, case studies offer rich data that enable an in-depth analysis of the studied phenomenon (Yin 2009). This is suitable for this research as the relational uncertainty and suitable organisational responses need to be investigated in-depth to identify causal relationships (de Bruin et al. 2002). Third, case studies are useful when there is a lack of extant theory explaining the investigated phenomenon (Eisenhardt and Graebner 2007). As explained in Section 2, there is a lack of current theory regarding relational uncertainty in servitization, effective organisational responses and the impact on service quality. The cases were thus suitable and relevant to answering our research questions. 


\subsection{Case studies}

Two industrial case studies are presented; both set in the UK electronics sector. The electronics sector is particularly useful for this research as it has seen an increasing trend of servitization due to global pressures to improve product performance and reduce energy use. The cases were strategically chosen based on similarities and differences. The chosen cases are set in similar contextual settings which offer an ideal basis for triangulating case findings and building theory (Lewis 1998) as well as mitigate the influence of observer bias on the obtained findings (Voss et al. 2002). We were thus able to replicate observations and ensure that case findings are not idiosyncratic (Eisenhardt and Graebner 2007). The cases differed with regard to the duration of the service relationships. At the point of data collection, the service dyads had existed for three (Case A) and six years (Case B). The choice of case studies enabled us to investigate the impact of relationship duration on the existence of relational uncertainty. Thus, the sampling strategy enabled an in-depth investigation into relational uncertainty in service dyads to further theory building.

Both service providers were internationally operating manufacturing companies that produced electronic products for water treatment such as actuators and pumps. The specific service dyads were identified during discussions with the providers based on specific research requirements. In addition to the typical case requirements outlined by e.g. Yin (2009), our case selection included the accessibility of both provider and customer for data collection. This led to the choice of successful inter-organisational collaboration with open sharing of information and strategic considerations. This is a suitable approach to case selection as it offers insights based on best practices which improve our understanding and theory building (Siggelkow 2007) as well as provide 
strong managerial implications (Barratt et al. 2011). The presented findings thus exemplify positive service relationships.

\subsection{Data collection}

The empirical data were gathered via multiple sources of evidence (Yin 2009). Semistructured interviews were conducted because this allowed for a detailed discussion of the interviewees' experiences with the possibility to clarify assumptions and misunderstandings. Particularly, interviews with open-ended questions have been highlighted as a suitable method to assess uncertainty perception (de Bruin et al. 2002). The interviewees were chosen based on their experience and levels of involvement in the cases with regard to the research focus. Ten and sixteen semi-structured interviews were collected for Cases A and B respectively as listed in Table 1. The interviews were collected in 2013, held face-to-face and one-to-one. They took between 20 and 60 minutes, were recorded and transcribed for analysis. In addition, secondary data including financial reports, service contracts and service reports was collected to validate findings and ensure internal and external validity (Lewis 1998).

\section{<Please insert Table 1 about here $>$}

The interviews followed a prepared protocol to guide the discussion. The interviewees were asked to reflect on the service exchange over the full case period (both during and prior to the contract signature) and describe their experience in the service dyad. This included the interviewees' expectations, critical events throughout the collaboration both positive and negative, their personal evaluation of the performance and lessons learnt (the full questionnaire is presented in the appendix). The questions enabled the researcher to gather a full picture of the case arrangement, the service relationship and the challenges through specific experiences described by the individual interviewees. 
The interviews did not specifically discuss uncertainty as this was found to bias interviewees (Kreye et al. 2013) and thus reduce the usefulness of the gathered findings (de Bruin et al. 2002). Instead, an indirect approach was followed to focus on the interviewees' experiences and challenges during the service set-up as recommended by the literature. This offered useful insights and a suitable basis for the data analysis of this research.

\subsection{Data analysis}

The unit of analysis is the service dyad. To achieve a contextually detailed account of the cases, the data were carefully analysed through systematic combining (Dubois and Gadde 2002). The data were initially coded in thematic categories based on the RQs and comprehensive literature review (Glaser 1992, pp. 45-77). Specifically, the conceptual framework (Figure 1) informed the initial coding structure. Susequently, the data were coded based on the researchers' understanding and interpretation of the data. The thematic categories emerged based on the empirical data (Walker and Myrick 2006) through systematically combining empirical data analysis, collection and the literature to facilitate theory building (Miles et al. 2014, pp. 292-293). Specifically, the coding structure was created and refined iteratively by identifying links between the investigated concepts (Miles et al. 2014). This allowed the researcher to create a cognitive map of the causes, effects and aim of organisational processes and identify links between local incidents in the case studies. The emerging meta-codes in turn enabled the cross-case comparison (Miles et al. 2014). Furthermore, the cases were written up as case reports and presented to the case companies for verification and discussion to give an opportunity to comment on observations and initial conclusions. This allowed for further clarifications and refinements of the conclusions. 


\section{Findings}

In this section, the findings are presented with regard to the case context, relational uncertainty, organisational responses and service quality.

\subsection{Case context}

The service agreements were a strategic move for both providers. For example, Provider A advertised that they do not only offer emergency repairs but also "on site overhaul \& testing, health checks (for the technical equipment) \& Preventative maintenance, (...) and firmware upgrades" (Company presentation, Provider A). This was supported by the necessary in-house facilities including a workshop for "testing \& certification, comprehensive spares holdings, overhaul \& Repair, and fault diagnosis" (Company presentation, Provider A). Similarly, services were also of increasing strategic importance for Provider B. The General manager (Provider B) explained: "Service is now becoming a huge factor. This is a new area for growth and for increased revenue. So we are looking to expand on service." The service agreements studied in this research can be seen as examples of the strategic incorporation of increasingly complex service activities in the providers' offerings. This makes the cases relevant industrial examples for the context of servitization.

Both cases focused on the maintenance of the service provider's products, inspecting the condition and repairing faults and breakdowns. The aim of both contracts was to "give the support the customer requires and to (...) [minimise] downtime" (Sales manager, Provider B). In both cases, the studied service exchange was the first contractually agreed service. Prior to the service agreement, the case companies had engaged for repairs and maintenance which were handled on a case-by-case basis when faults occurred. The engagement prior to the service contract helped the providers gain 
experience with their customers as highlighted by the Sales manager (Provider A): "so before we had this contract, we had this trial run which helped us look at volume, how much work, response time, expectation. So it gave us a little feel about the contract." Thus, both cases included a formalised framework agreement where previously only adhoc service support was offered.

\subsection{Relational uncertainty}

Both cases showed evidence of relational uncertainty arising particularly from the limited prior experience in the service dyads. In Case A, the customer had a prior experience with Competitive provider A before engaging in the service arrangement with Provider A. The Maintenance electrician (Customer A) described the relational uncertainty as follows: "In the beginning, I did feel more comfortable speaking to [Competitive provider A]." The General manager (Provider A) explained the situation: "they had a very good relationship with [Competitive provider A] and anytime we made a mistake, it was quite quickly communicated through the [Customer A] business. " This demonstrates the difficulty the service partners in Case A had at the early stages of their engagement.

In later stages, it was particularly Provider A who experienced relational uncertainty. The reasons for this observation were the internal processes of Customer A. For example, Customer A changed procedures for receiving the services as Electrician 2 (Customer A) explained:

"I used to ring the foreman [of Provider A] and say, 'I've got this piece of equipment. Are you okay to go and fix it now?' Then I'd ring the office and get him a job number. But it doesn't work like that anymore. We just have to request a job and send it off. And then it might take three or four week before [Provider A] get in touch with me."

The change in procedures required Customer A to process information not only locally 
on individual sites but also globally within the service organisation. This global information processing constituted a problem for Customer A which caused substantial delays from requests to actual service activities. Another reason of the internal processes of Customer A causing relational uncertainty for Provider A was the type of repairs Customer A requested. Many of these repairs should have been solved by Customer A's own engineers. The Service manager (Provider A) explained: " a lot of times, they'd ring us up and say 'it doesn't work. 'And we get out there and all it was we had to change the battery, which is something they could or should be able to do. (...) we were getting quite a number of these jobs." This suggests that the customer lacked technical capabilities to provide the front-line service activities. Thus, Customer A lacked the necessary organisational capabilities to receive the service which in turn caused relational uncertainty for Provider A.

In Case $\mathrm{B}$, the companies faced high levels of relational uncertainty particularly in the early stages of their engagement. This manifest itself particularly during service visits as the Engineering Supervisor described: "there were visits [in the early stages] where an engineer has turned up unannounced. (...) I had to send the guy away because nobody knew who he was." Thus, the missing routines and personal relationships between provider and customer engineers caused relational uncertainty in the early stages of the service engagement in Case B.

In later stages, it was Customer B who experienced relational uncertainty. The Engineering supervisor (Customer B) explained:

"[They need to] work on their communication. Even if it's going to take a couple of days to put a quote together just a quick email [would be enough]. (...) But, there's a gap. It's like taking your car in the garage and you don't hear anything for two days, then you have to ring up and say, "Where's my car?" It should be the other way around."

Customer B's relational uncertainty arose from the provider's missing capabilities. 
Provider B made the strategic decision to rotate their back-office staff to gain operational flexibility. Administrator 1 described "Everyone was given redefined job roles to try and make things work a little better." This job redefinition caused a lack of clear procedures for Provider B's back office which created difficulties because backoffice staff often felt unsure about, for example, their tasks, key contact persons and communication routes. This lack of procedures meant that no clear communication patterns were developed between provider and customer staff. The Engineering supervisor (Customer B) explained this: "You have had a change of personnel in the service office recently. (...) if you had the same person dealing with you all the time, they'd know exactly what I need." Thus, in Case B, the Provider's lack of suitable capabilities created relational uncertainty for Customer B.

\subsection{Organisational responses}

To reduce the relational uncertainty, the service partners built personal relationships between their staff. Provider A engaged in getting-to-know-each-other activities to reduce the initial high levels of relational uncertainty. The Service manager (Provider A) explained:

"in the initial stages, myself an another chap visited a lot of sites and met with the engineers on site - the guys who are the field service engineers. We took on bacon sandwiches and gave a little bit of a presentation and discussed equipment with them. So there was a lot of interaction in the early part."

These activities resulted in close personal ties between provider and customer employees. For example, the Service manager (Provider A) described his relationship with Customer A's Site manager: "If he [the site manager] asks us to go to site, there's no way we could say no to him. Even if he asked us to go on Christmas Day, we couldn't say no." This shows how close personal ties helped the employees not only to develop 
trust but also build leverage with their partner organisation to jointly deal with difficult situations. Customer A replicated this assessment and highlighted specifically their respect for the Provider A's Service manager. Electrician 1 (Customer A) described: "their service manager was quite helpful really. You could call him up and he'd bend over backwards and help you out with anything." Thus, reciprocal trust arising from close personal ties was a key element to resolve relational uncertainty in Case A.

Similarly, Provider B reduced their relational uncertainty by establishing personal routines of the customer staff. The Service engineer 1 (Provider B) explained:

"I quickly established that at 10 o'clock in the morning, the [staff at Customer B] like to go for a tea break. (...) So, we go to the café around the corner and I found that if you buy [Service manager, Customer B] breakfast, the rest of the day, he will leave you alone. So if the amount you saved for £5, it is sure bliss."

Adjusting own work patterns around customer routines helped Provider B to overcome challenges during service visits. This helped them to reduce relational uncertainty in the service dyad.

In addition to these approaches, the case companies also targeted their activities at the cause of the relational uncertainty, i.e. the internal issues of their service partners. Provider A organised and executed training workshops for the customer's engineers where they offered technical education for servicing their products. The Service manager (Provider A) explained: “I just mentioned it to [our Sales manager]. I said 'We're getting called out for a lot of silly little jobs.' And he thought of an opportunity here and took upon himself to train the people." The workshops thus targeted the lacking technical capabilities of Customer A's in-house engineers. The Sales manager (Provider A) described the workshops: "we go through the range of [equipment] and show them how to set limits, adjust switches and carry out basic fault finding 
diagnostics. The stuff that they were calling us out to do." By improving the technical skills of the customer's engineers, Provider A reduced their own relational uncertainty. In comparison, it was Provider B's redefinition of back-office roles that caused relational uncertainty for Customer B. This was resolved informally by Provider B's front-office staff. Service engineer 2 (Provider B) explained: "Personally, I always phone up one or two days prior to the visit just to make sure that everything has been put in place and they are expecting me". Provider B's front-office staff fulfilled some of the administrative tasks usually fulfilled by back-office staff. This ensured that relevant information was processed as and when required and communicated to Customer B. Thus, the informal procedures instigated by individual service engineers resolved the lack of formal procedures within Provider B.

\subsection{Service quality}

Provider A delivered a high technical quality of their service. The Service manager (Provider A) explained: "9 times out of 10 jobs go swimmingly. We have no problems at all." Customer A mirrored this positive assessment as their Team leader explained: "they provided me with the service that I wanted." In addition, the functional quality of the service offering was also high. The Team leader (Customer A) continued his explanation: "You start getting a relationship with the people, the managers and their technicians. Also the craftsmen [i.e. the customer's in-house engineers] do." This suggests an overall high level of customer satisfaction with the provided service. However, some of Customer A's engineers assessed this more critically. Electrician 1 (Customer A) described: "they have always been helpful. But I think sometimes some of the men they send out don't particularly know that much more than us but they can get all the parts so they can take the equipment away and then deal with it." This description shows that the customer also assessed the functional quality based on their 
own in-house skills.

For Case B, the technical quality of the provided service fell below the customer's expectations. This was exemplified by the Engineering Supervisor's (Customer B) statement that Provider B does not "know exactly what I need" (see also Section 4.2). In comparison, the functional quality of their offering was evaluated highly. The Mechanical Engineer (Customer B) explained “He (one of Provider B's service engineers) is really good. He listened to what I suggested which showed they were willing." Provider B summarised their assessment of the delivered service quality as follows: "we have a lot of ongoing work with them, we're talking to them about so many different things. [And this says to me] 'Look, you've done a good job'”' (General manager, Provider B). This description shows that the overall level of provided service quality was high which was visible in Customer B's purchasing of further service activities.

Table 2 summarises the observations from the two case studies.

\section{<Please insert Table 2 about here $>$}

\section{Discussion}

This section discusses the findings with regard to the three investigated elements (see also Figure 1): relational uncertainty, organisational responses and service quality. Finally, the research limitations are outlined.

\subsection{Relational uncertainty}

The case findings showed that relational uncertainty was distinct from other uncertainty types and existed between the partners in the service dyads. Our observations show that relational uncertainty could be experienced by provider and customer depending on their partner's abilities and intentions to receive or provide (parts of) the service. For 
example, the inability of Customer A to process information internally caused relational uncertainty for Provider A as a lack of trust in the available information in databases and local engineers. Similarly, the lack of back-office processes of Provider B caused relational uncertainty for Customer B with regard to communicating the relevant information prior to service visits. The reason for this observation can be found in the operational dependence of the service partners (Lacoste and Johnsen 2015). Inputs from both provider and customer are required during the service encounter (Lacoste and Johnsen 2015). Thus, the inability of one partner to provide the necessary information causes relational uncertainty for the other partner. In other words, in service dyads high levels of relational uncertainty arise either for the service provider (when their customer does not provide the relevant input information) or for the customer (when the provider does not provide the relevant information). Thus, in service dyads, relational uncertainty is unidirectional.

This characterisation complements traditionally conceptualised uncertainty types and links specifically to organisational uncertainty as the gap between the capabilities an organisation possesses and its needs (Galbraith 1974). The inability to provide relevant information can be described as a gap in the organisational capabilities and thus as organisational uncertainty. For example, Customer A possessed capabilities that processed information by the service engineers locally on their individual sites but was unable to process this information within the whole service organisation. Thus, Customer A faced organisational uncertainty due to the difference of organisational capabilities they possessed in comparison to the capabilities they needed for the service arrangement with Provider A. Conversely, Provider B faced organisational uncertainty because they lacked formal procedures that ensured the communication of the required information prior to a service visit. Thus, the partner's unresolved organisational 
uncertainty was the ultimate cause for the relational uncertainty experienced within the service dyads.

In summary, our findings identify the following two characteristics of relational uncertainty in service dyads. First, relational uncertainty is a unidirectional concept that arises particularly for one partner in the service dyad - either provider or customer. Second, relational uncertainty arises from the partner's unresolved organisational uncertainty, i.e. their lacking internal capabilities to receive or provide (parts of) the service. Combining these characteristics with the definition of relational uncertainty in the social psychology literature (see Section 2.2.1), a suitable definition of relational uncertainty in organisational contexts can be derived as follows:

Relational uncertainty is the inability to predict and explain the actions of a partnering organisation due to a lack of knowledge about their abilities and intentions.

This definition and the characterisation of relational uncertainty in service dyads through empirical observation are core contributions of this research.

\subsection{Organisational responses}

Our findings showed two main approaches of organisations to respond to relational uncertainty. The first response was to form relationships between service staff on different levels. In Case A, these relationships existed between core decision makers in both organisations (for example Provider A's Service manager and Customer A's Site manager). The relationships were characterised by close personal ties and increased levels of trust. In contrast for Case B, these relationships were localised between engineers and manifested themselves through adjusting to the customer's routines. These processes have also been described as relational capabilities which are required by organisations to perform in and benefit from business relationships (Srivastava et al. 2001, Kreye et al. 2015). Our findings extend these descriptions by showing that these 
capabilities need to be built in the dyad in response to relational uncertainty. Thus, one organisational response to relational uncertainty in service dyads is to build relational capabilities utilising the multiple channels of customer contact.

The second response is to address the cause of relational uncertainty, i.e. the partner's unresolved organisational uncertainty. In Case A, the provider recognised the customer's lacking organisational capabilities and utilised training workshops to improve the technical skills of Customer A's engineers. Traditional models argue against such an engagement because enabling a customer to perform services in-house will reduce the number of activities they outsource to their provider (Bustinza et al. 2010). This in turn reduces the amount of service sales and hence the economic performance of the provider's service business. The observations in Case A can be explained by Provider A's motivation to resolve their relational uncertainty. Specifically, they resolved its source which was Customer A's unresolved organisational uncertainty in terms missing technical skills. Thus, the concept of relational uncertainty offers explanatory value for the observations in Case A which traditional models fail to explain. Specifically the logic of OIPT enabled the identification of causal links between organisational activities as a response to the experienced relational uncertainty to improve operations within the service dyad.

Applying OIPT logic also enabled the identification of managerial actions in response to experienced uncertainty. For example, the unresolved organisational uncertainty in Case B concerned Provider B's lacking communication of relevant service information. Provider B reduced their organisational uncertainty through informal processes as explained by, for example, Service engineer 2 who always called Customer B prior to a service visit to ensure site access. Provider B thus coupled their front-office and back-office through their service engineers who fulfil both sets of 
activities. This has been described as a viable approach for service provision (Metters and Vargas 2000) because it can create flexibility and responsiveness (Zomerdijk and de Vries 2007). However, these activities were ad-hoc approaches by the service engineers rather than a strategic decision by the service management. Provider B could also have adopted one of the following two strategies to reduce the relational uncertainty in the service dyad. First, they could establish the relevant organisational capabilities in the form of formal procedures in the back-office. This would ensure that the needed information is communicated to Customer B irrespective of the specific responsible person in the back-office. Second, they could couple front-office and backoffice activities (Metters and Vargas 2000). Specific service engineers would then be tasked with delivering the service and fulfilling the relevant administrative tasks. These strategies would reduce the unresolved organisational uncertainty of Provider B and hence reduce the relational uncertainty in the service dyad. Our conceptualisation of relational uncertainty thus enabled the identification of suggestions for managerial actions to ensure service quality.

Finally we did not find an impact of time on reducing the experienced relational uncertainty. Both cases showed instances of relational uncertainty for both service dyads despite the difference regarding relationship duration. This suggests that the increased duration of the service relationship does not reduce relational uncertainty. This contrasts suggestions in the literature that describe the increased trust of longstanding ties (Bastl et al. 2012) which in turn should reduce relational uncertainty. Our findings can be explained by the characteristic of relational uncertainty being caused by the partner's unresolved organisational uncertainty. The unresolved organisational uncertainty means that the partner lacks the ability to collaborate for a joint goal. Thus, the long duration of a service relationship might increase the trust in the partner's 
intentions to collaborate but not (necessarily) in the partner's ability to do so. Thus long-standing inter-organisational relationships may also face relational uncertainty.

\subsection{Service quality}

The organisational responses to relational uncertainty changed the level of experienced service quality in terms of functional and technical quality. The functional quality of the delivered service was high for both cases. The statements presented in the findings can be attributed to the empathy, assurance and responsiveness (Parasuraman et al. 1988, Cronin and Taylor 1994) of the providers' service employees. This suggests that the functional quality of service offerings is influenced by the care of the individual service employee at the moment(s) of service delivery. This aligns with descriptions for B2C services that highlight factors such as empathy and assurance in the context of service quality (Parasuraman et al. 1988, Cronin and Taylor 1994). The insights of the functional quality were further influenced by the nature of the relationship in the service dyad. Both cases were selected as examples of positive customer relationships (see Section 3.1 for case selection). This suggests that in service dyads, the evaluation of the functional quality of the service offering is impacted by the relationship quality (Ulaga and Eggert 2006). Thus, a positive customer relationship increases also the level of functional quality in service dyads.

In contrast, the technical quality differed between the cases. The high technical quality in Case A was observed because Provider A delivered what the customer expected and needed. In contrast, Customer B assessed the technical quality as low because of the provider's lack of "knowing what we need" (Eng. Supervisor, Customer B). These observations can be linked to the organisational uncertainty in both cases. Provider B faced unresolved organisational uncertainty and was thus not able to deliver what Customer B expected. In comparison, the organisational uncertainty in Case A 
was situated with Customer A. Provider A resolved this organisational uncertainty by offering additional activities such as training workshops. These additional activities further increased the technical quality of Provider A's offering. Thus, the assessment of the technical quality depended on the provider's abilities to resolve the cause of the relational uncertainty in the service dyad, i.e. the partner's unresolved organisational uncertainty.

\subsection{Limitations}

Due to the exploratory nature and qualitative methodology of this research, limitations apply to the presented research. Case study research is often associated with observer bias and subjectivity in interpreting the findings (Yin 2009). These limitations were mitigated by triangulating the interview data with secondary data to improve the reliability and limit the influence of subjectivity on the analysis (Yin 2009). Moreover, the results show in-depth insights for the UK electronics sector and are thus aligned with the contingency approach that highlights the dependency on research and business contexts (Barratt et al. 2011). Furthermore, qualitative research findings typically have limited generalizability. This was mitigated by presenting multiple case studies that enabled the replication of findings across cases (Voss et al. 2002). However, the cases represented successful service dyads limiting the insights to these settings.

\section{Conclusions}

This paper described how organisations experience relational uncertainty in service dyads and how they reduce relational uncertainty through suitable organisational responses to increase service quality. Presenting in-depth insights from two industrial case studies of service dyads, we were able to discern relational uncertainty as a concept distinct from traditional uncertainty types such as environmental and organisational 
uncertainty. We characterised relational uncertainty as a unidirectional construct which can be caused by the unresolved organisational uncertainty of the service partner. Further, we observed that organisational responses for reducing relational uncertainty impacted different parts of the service quality. Responses to reducing relational uncertainty directly through formal and informal relational governance mechanisms increased the functional quality of the service offering. In comparison, addressing relational uncertainty indirectly by reducing its cause - i.e. the partner's unresolved organisational uncertainty - increased the technical quality.

Our research contributes to the literature in two distinct ways. The first contribution is the introduction of relational uncertainty to the literature on service dyads and servitization. In this context relational uncertainty refers to the inability to predict and explain the actions of a partnering organisation due to a lack of knowledge about their abilities and intentions. We found two main characteristics of relational uncertainty in service dyads. First, it is unidirectional, i.e. high levels of relational uncertainty arise either for the service provider or for the customer. Second, it is caused by unresolved organisational uncertainty of the service partner. The second contribution is the causal links between suitable organisational responses to reduce relational uncertainty and their effects on service quality. Specifically our research showed how different organisational responses affected the functional and technical quality of the service offering. Our research thus furthers theory building in service dyads.

Our work offers strong managerial implications. We showed that the existence of relational uncertainty affects operations in service dyads specifically through the changes it creates in the assessment of service quality and hence the performance of the service business. Moreover, our research showed the importance of addressing organisational challenges of the service partners to reduce the relational uncertainty 
experienced and increase the levels of service quality as follows. When the provider faces high levels of organisational uncertainty, managers need to prioritise the development of relevant service capabilities. If these capabilities are not developed, the technical quality of the service offering can fall below customer expectations. When the customer faces high levels of organisational uncertainty, the provider has an opportunity to support the customer in resolving this uncertainty and thus improving the technical quality of the service offering. These implications show not only the potential threat of unresolved uncertainty but also potential opportunities in collaboratively resolving the uncertainty.

Our work points towards different areas for further research. First, our findings showed the relevance of relational uncertainty in close and successful service dyads. Adverse relationships might face even higher levels of relational uncertainty which would broaden our understanding of the concept and its characteristics. Second, further research is needed to investigate the factors affecting service quality in service dyads. This would enable the identification of suitable constructs and measures. Third, relational uncertainty may exist also in other settings of inter-organisational collaboration such as product exchanges, supply chains or other value networks. Our research showed the relevance and explanatory value of relational uncertainty in organisational settings. Further work is needed to expand on these insights and characterise relational uncertainty and its effects in other organisational collaborations.

\section{Acknowledgements:}

The author thanks the two anonymous reviewers and the editor-in-chief for their constructive and helpful comments during the submission of this article. The author further thanks Philip Cash for his constructive comments on earlier versions of this paper. Finally, the author thanks the eight anonymous reviewers of earlier submissions 
of this work which have contributed to shaping the research argument.

\section{References}

Antioco, M., Moenaert, R. K., Lindgreen, A., and Wetzels, M. G. M., 2008.

Organizational antecedents to and consequences of service business orientations in manufacturing companies. Journal of the Academy of Marketing Science, 36 (3), $337-358$.

Baines, T. and Lightfoot, H. W., 2014. Servitization of the manufacturing firm: Exploring the operations practices and technologies that deliver advanced services. International Journal of Operations \& Production Management, 34 (1), 2-35.

Barratt, M., Choi, T. Y., and Li, M., 2011. Qualitative case studies in operations management: Trends, research outcomes, and future research implications. Journal of Operations Management, 29 (4), 329-342.

Bastl, M., Johnson, M., Lightfoot, H., and Evans, S., 2012. Buyer-supplier relationships in a servitized environment: An examination with Cannon and Perreault's framework. International Journal of Operations \& Production Management, 32 (6), 650-675.

Baveja, S., Singh, J. G., and Ledingham, D., 2004. From Products to Services: Why It's Not So Simple. Harvard Management Update, 9 (4), 3-5.

Beckman, C. M., Haunschild, P. R., and Phillips, D. J., 2004. Friends or Strangers? Firm-Specific Uncertainty, Market Uncertainty, and Network Partner Selection. Organization Science, 15 (3), 259-275. 
Benedettini, O., Neely, A., and Swink, M., 2015. Why do servitized firms fail? A riskbased explanation. International Journal of Operations \& Production Management, 35 (6), 946-979.

Berger, C. R., 1986. Uncertain Outcome Values in Predicted Relationships Uncertainty Reduction Theory Then and Now. Human Communication Research, $13(1), 34-38$.

Breidbach, C. F., Kolb, D. G., and Srinivasan, A., 2013. Connectivity in Service Systems: Does Technology-Enablement Impact the Ability of a Service System to Co-Create Value? Journal of Service Research, 16 (3), 428-441.

de Bruin, W. B., Fischbeck, P. S., Stiber, N. A., and Fischhoff, B., 2002. What Number is 'Fifty-Fifty'?: Redistributing Excessive 50\% Responses in Elicited Probabilities. Risk Analysis: An International Journal, 22 (4), 713-723.

Bustinza, O. F., Arias-Aranda, D., and Gutierrez-Gutierrez, L., 2010. Outsourcing, competitive capabilities and performance: an empirical study in service firms. International Journal of Production Economics, 126 (2), 276-288.

Caldwell, N. and Howard, M., 2014. Contracting for complex performance in markets of few buyers and sellers. International Journal of Operations \& Production Management, 34 (2), 270-294.

Carey, S., Lawson, B., and Krause, D. R., 2011. Social capital configuration, legal bonds and performance in buyer-supplier relationships. Journal of Operations Management, 29, 277-288.

Cousins, P. D., Handfield, R. B., Lawson, B., and Petersen, K. J., 2006. Creating supply 
chain relational capital: The impact of formal and informal socialization processes. Journal of Operations Management, 24 (6), 851-863.

Cronin, J. J., Brady, M. K., and Hult, G. T. M., 2000. Assessing the Effects of Quality, Value, and Customer Satisfaction on Consumer Behavioral Intentions in Service Environments. Journal of Retailing, 76 (2), 193-218.

Cronin, J. J. and Taylor, S. A., 1994. SERVPERF Versus SERVQUAL : Reconciling Performance-Based and Measurement of Service Quality. Journal of Marketing, 58 (January), 125-132.

Daft, R. L. and Lengel, R. H., 1986. Organizational Information Requirements, Media Richness and Structural Design. Management Science, 32 (5), 554-571.

Dubois, A. and Gadde, L. E., 2002. Systematic combining: An abductive approach to case research. Journal of Business Research, 55 (7), 553-560.

Dwyer, F. R., Schurr, P. H., and Oh, S., 1987. Developing Buyer-Seller Relationships. Journal of Marketing, 51 (2), 11-27.

Dyer, J. H. and Singh, H., 1998. The Relational View: Cooperative Strategy and Sources of Interorganizational Competitive Advantage. The Academy of Management Review, 23 (4), 660-679.

Eggert, A. and Ulaga, W., 2002. Customer perceived value: a substitute for satisfaction in business markets? Journal of Business \& industrial marketing, 17 (2/3), 107 118.

Eisenhardt, K. M. and Graebner, M. E., 2007. Theory Building from Cases: Opportunities and Challenges. Academy of Management Journal, 50 (1), 25-32. 
Fynes, B., de Búrca, S., and Marshall, D., 2004. Environmental uncertainty, supply chain relationship quality and performance. Journal of Purchasing and Supply Management, 10 (4-5), 179-190.

Galbraith, J. R., 1974. Organization Design: An Information Processing View. Interfaces, 4 (3), 28-36.

Glaser, B. G., 1992. Basics of grounded theory analysis. Mill Valley, CA: Sociological Press.

Grönroos, C., 1988. Service Quality: The Six Criteria of Good Perceived Service Quality. Review of Business, 9 (Winter), 10-13.

Grönroos, C., 2011. A service perspective on business relationships: The value creation, interaction and marketing interface. Industrial Marketing Management, 40 (2), $240-247$.

Hawkins, T. G., Gravier, M. J., Berkowitz, D., and Muir, W. A., 2015. Improving services supply management in the defense sector: How the procurement process affects B2B service quality. Journal of Purchasing and Supply Management, 21 (2), 81-94.

Hult, G. T. M., Ketchen, D. J., and Slater, S. F., 2004. Information Processing, Knowledge Development, and Strategic Supply Chain Performance. Academy of Management Journal, 47 (2), 241-253.

Kellermann, K. and Reynolds, R., 1990. When Ignorance Is Bliss The Role of Motivation to Reduce Uncertainty in Uncertainty Reduction Theory. Human Communication Research, 17 (1), 5-75. 
Knobloch, L. K. and Solomon, D. H., 1999. Measuring the sources and content of relational uncertainty. Communication Studies, 50 (4), 261-278.

Kreye, M. E., 2016. Employee motivation in Product-Service-System providers. Production Planning \& Control, in print.

Kreye, M. E., Goh, Y. M., Newnes, L. B., and Goodwin, P., 2012. Approaches of Displaying Information to Assist Decisions under Uncertainty. Omega International Journal of Management Science, 40 (6), 682-692.

Kreye, M. E., Newnes, L. B., and Goh, Y. M., 2013. Information availability at the competitive bidding stage for service. Journal of Manufacturing Technology Management, 24 (7), 976-997.

Kreye, M. E., Newnes, L. B., and Goh, Y. M., 2014. Uncertainty in competitive bidding - a framework for product - service systems. Production Planning \& Control, 25 (6), 462-477.

Kreye, M. E., Roehrich, J. K., and Lewis, M. A., 2015. Servitising manufacturers: the impact of service complexity and contractual and relational capabilities. Production Planning \& Control, 26 (14), 1-14.

Lacoste, S. and Johnsen, R. E., 2015. Supplier-customer relationships: A case study of power dynamics. Journal of Purchasing and Supply Management, 1-12.

Lewis, M. W., 1998. Iterative triangulation: a theory development process using existing case studies. Journal of Operations Management, 16 (4), 455-469.

Lui, S. S. and Ngo, H.-Y., 2004. The role of trust and contractual safeguards on cooperation in non-equity alliances. Journal of Management, 30 (4), 471-485. 
Metters, R. and Vargas, V., 2000. A typology of de-coupling strategies in mixed services. Journal of Operations Management, 18 (6), 663-682.

Miles, M. B., Huberman, A. M., and Saldaña, J., 2014. Qualitative Data Analysis: A Methods Sourcebook. 3rd ed. Thousand Oaks, CA, USA: Sage Publications, Inc.

Milliken, F. J., 1987. Three types of perceived uncertainty about the environment: State, effect, and response uncertainty. Academy of Management Review, 12 (1987), $133-143$.

Neely, A., 2008. Exploring the Financial Consequences of the Servitization of Manufacturing. Operations Management Research, 1 (2), 103-118.

Oosterhuis, M., van der Vaart, T., and Molleman, E., 2011. Perceptions of technology uncertainty and the consequences for performance in buyer-supplier relationships. International Journal of Production Research, 49 (20), 6155-6173.

Parasuraman, A., Zeithaml, V. A., and Berry, L., 1988. SERVQUAL: A Multiple Item Scale for Measuring Consumer Perceptions of Service Quality. Journal of Retailing, 64 (1), 12-40.

Poppo, L. and Zenger, T., 2002. Do formal contracts and relational governance function as substitutes or complements? Strategic Management Journal, 23 (8), 707-725.

Reim, W., Parida, V., and Sjödin, D. R., 2016. Risk management for product-service system operation. International Journal of Operations \& Production Management, $36(6), 665-686$.

Reinartz, W. and Ulaga, W., 2008. How to Sell Services MORE Profitably. Harvard Business Review, 86 (5), 90-96. 
Roehrich, J. K. and Lewis, M. A., 2010. Towards a model of governance in complex (product-service) inter-organisational systems. Construction Management and Economics, 28 (11), 1155-1164.

Rosenbloom, B., 2007. Multi-channel strategy in business-to-business markets: Prospects and problems. Industrial Marketing Management, 36 (1), 4-9.

Ruffini, F. J., Boer, H., and Riemsdijk, M. J. Van, 2000. Organisation design in operations management. International Journal of Operations \& Production Management, 20, 860-879.

Sampson, S. E., 2012. Visualizing Service Operations. Journal of Service Research, 15 (2), 182-198.

Schmenner, R. W., 1986. How Can Service Businesses Survive and Prosper? Sloan Management Review, 27 (3), 21-32.

Siggelkow, N., 2007. Persuasion with case studies. Academy of Management Journal, $50(1), 20-24$.

Srivastava, R. K., Fahey, L., and Christensen, H. K., 2001. The resource-based view and marketing: The role of market-based assets in gaining competitive advantage. Journal of Management, 27 (6), 777-802.

Tax, S. S., McCutcheon, D., and Wilkinson, I. F., 2013. The Service Delivery Network (SDN): A Customer-Centric Perspective of the Customer Journey. Journal of Service Research, 16 (4), 454-470.

Ulaga, W., 2003. Capturing value creation in business relationships: A customer perspective. Industrial Marketing Management, 32 (8), 677-693. 
Ulaga, W. and Eggert, A., 2006. Relationship value and relationship quality:

Broadening the nomological network of business-to-business relationships.

European Journal of Marketing, 40 (3/4), 311-327.

Vandermerwe, S. and Rada, J., 1988. Servitization of Business: Adding Value by Adding Services. European Management Journal, 6 (4), 314-324.

Vargo, S. L. and Lusch, R. F., 2008. Service-dominant Logic: Continuing the Evolution. Journal of the Academy of Marketing Science, 36 (1), 1-10.

Voss, C., Tsikriktsis, N., and Frohlich, M., 2002. Case research in operations management. International Journal of Operations \& Production Management, 22 (2), 195-219.

Walker, D. and Myrick, F., 2006. Grounded Theory: An Exploration of Process and Procedure. Qualitative Health Research, 16 (4), 547-559.

Yin, R. K., 2009. Case study research: design and methods. Los Angeles, CA, USA: SAGE Publications.

Zomerdijk, L. G. and de Vries, J., 2007. Structuring front office and back office work in service delivery systems. International Journal of Operations \& Production Management, 27 (1), 108-131. 


\section{Appendix}

Exemplar interview questions:

- Can you summarise for me what the aim or purpose of this service was?

- How much experience have you had with the customer prior to this contract (in years)?

- Think of the time of pre-contract negotiations. Can you describe any positive or negative events in this time?

- How would you characterise the pre-contract negotiation with the customer?

- In the beginning of this contract, what were your expectations of this contract and the relationship with the customer?

- In the course of this contract and your interaction with the customer from start to end, can you describe what went well and what went wrong?

- How would you rate the overall performance of this contract?

- What are the lessons learnt from this contract? 


\section{Figures and Tables}

Table 1: Interviewees for both case studies

\begin{tabular}{|l|l|l|}
\hline \multirow{7}{*}{ Provider } & Case A & Case B \\
& Service engineer & Service engineer 1 \\
Sr Service engineer & Service engineer 2 \\
& Service manager & Service engineer 3 \\
& Sales manager & Administrator 1 \\
& General manager & Service planner \\
& & Service coordinator \\
& & Office manager \\
& & Sales manager 1 \\
& & Sales manager 2 (semi-retired) \\
& & Accounts manager \\
& & Service manager 1 \\
& & General manager \\
\hline \multirow{7}{*}{ Customer } & Electrician 1 & Mechanical engineer \\
& Electrician 2 & Engineering Supervisor \\
& Technical manager 1 & Administrator 2 \\
& Technical manager 2 & Service manager 2 \\
& Eng. Supervisor & \\
\hline
\end{tabular}


Table 2: Summary of observations from Cases A and B

\begin{tabular}{|c|c|c|c|}
\hline & Relational uncertainty & Organisational responses & Service quality \\
\hline Case A & $\begin{array}{l}\text { High levels of relational uncertainty for Provider A } \\
\text { This relational uncertainty arose from Customer A's } \\
\text { lacking capabilities to receive the service, } \\
\text { demonstrated through, for example: } \\
\text { - Lacking ability to process service-relevant } \\
\text { information internally in a timely manner } \\
\text { - Lacking technical ability of Customer A's } \\
\text { engineers to do simple repairs }\end{array}$ & $\begin{array}{l}\text { Resolution of Provider A's relational uncertainty } \\
\text { through building personal relationships between } \\
\text { core decision makers of Provider A (e.g. their } \\
\text { service manager) and Customer A (e.g. their } \\
\text { Engineering Supervisor) } \\
\text { Resolution of the source of relational uncertainty, } \\
\text { i.e. Customer A's lack in capabilities, through } \\
\text { formal education of customer's engineers in } \\
\text { technical competencies in e.g. workshops }\end{array}$ & $\begin{array}{l}\text { Resolution of relational uncertainty addressed } \\
\text { functional quality through improving how the } \\
\text { service was delivered } \\
\text { Resolution of Customer A's lacking capabilities } \\
\text { addressed the technical quality of the service } \\
\text { offering because it increased the amount of service } \\
\text { activities delivered by Provider A }\end{array}$ \\
\hline Case B & $\begin{array}{l}\text { High levels of relational uncertainty for Customer B } \\
\text { This relational uncertainty arose from Provider B's } \\
\text { lacking capabilities to communicate relevant } \\
\text { information to Customer B. The reason for this was } \\
\text { the rotation of back-office staff resulting in a lack of } \\
\text { continuation and clear procedure that defines what } \\
\text { type of information needs to be communicated to } \\
\text { Customer B prior to service visits. }\end{array}$ & $\begin{array}{l}\text { Reduction of relational uncertainty through } \\
\text { establishing routines of Customer B's engineering } \\
\text { staff by Provider B's service engineers. } \\
\text { Reduction of the source of relational uncertainty, } \\
\text { i.e. Provider B's lacking capabilities, through } \\
\text { informal individual processes from service } \\
\text { engineers (front-office staff) to accommodate for } \\
\text { missing administrative procedures (back-office } \\
\text { processes) }\end{array}$ & $\begin{array}{l}\text { Resolution of relational uncertainty improved the } \\
\text { functional quality of the service offering because it } \\
\text { improved how the service was delivered } \\
\text { Reduction of Provider B's lacking capabilities } \\
\text { improved technical quality of the service offering; } \\
\text { however, this remained below Customer B's } \\
\text { expectations. }\end{array}$ \\
\hline
\end{tabular}


